\title{
UM CERTO MODO DE FALAR SOBRE A PROVA DE GÖDEL*
}

\author{
João José R. L. de Almeida
}

\section{Resumo:}

Este texto parte de duas premissas: (1) que uma atividade na qual tenhamos sido adestrados até o ponto de desenvolver um domínio sobre o modo apropriado de aplicação de regras para a sua execução possa ser chamada de “jogo de linguagem”, e (2) que uma investigação detetivesca seja um jogo deste tipo. A seguir, aplica-se rigorosamente esta forma de investigação sobre três seções que fazem parte do Anexo III da Parte I das "Observações Sobre os Fundamentos da Matemática". No entanto, o que sistematicamente se examina com relação ao texto não é um evento empírico cuja comprovação justifica a metodologia de coleta de indícios e de entrelaçamento inferencial admitidamente em uso no jogo de linguagem da investigação detetivesca. Um crime, um desfalque financeiro ou uma espionagem empresarial seriam ocorrências adequadas a esta forma de perquirição. Mas, em vez da catalogação de rastros para a constatação de um fato, aplicamos a mesma metodologia para coletar uma especulação filosófica ou, dito de modo inverso, uma pergunta filosófica passa a ser respondida aqui pelo mesmo modo de uma hipótese factual. E esta se enuncia da seguinte maneira: se o bloco textual puder ser tomado como peça literária, evidenciaremos com isto uma finalidade terapêutica do texto como um todo? Nossa investigação previsivelmente se frustra, pois o que realmente se evidencia é que não se pode no tipo pretendido de jogo apresentar evidências para revelar hipóteses filosóficas, já que estas não preservam rastros perceptíveis na anatomia dos dados. Estaríamos misturando coisas diferentes. A pergunta filosófica, no entanto, permanece, ainda que à revelia do plano empírico: "como muda o leitor deste texto?". Aparentemente, uma mudança como esta só seria possível mediante o reconhecimento dos modos de trabalho da nossa linguagem e da maneira como formulamos e encaminhamos nossas perguntas. Nada a ver com o conhecimento indiciário, nada a ver com qualquer elemento que possamos certificar pela percepção.

Palavras-chave: Wittgenstein; jogo de linguagem da leitura; narrativa; opacidade; efeito terapêutico.

Há uma razão para empreender uma investigação sobre uma das formas narrativas de Wittgenstein em particular: a suspeita de que a narrativa seja para o autor o veículo terapêutico por excelência em que tipicamente pretende provocar mudança de atitude no leitor. Se isto se verifica, tal mudança estaria condicionada pelo que se reputa como "acaso terapêutico", que, por sua vez, também estaria condicionado pelo que se compreende como "forma narrativa". Se uma cumplicidade circular como esta, composta por notórios clichês tais como o par de palavras associadas "condição/condicionado", além da palavra

\footnotetext{
* DOI - 10.29388/978-65-86678-51-2-0-f-417-436
} 
"narrativa" e das expressões "forma narrativa" e "acaso terapêutico", for razão suficiente para uma investigação como a que agora empreendemos, o que temos a fazer é esclarecer o uso destes termos e verificar se a nossa suposta condição leva realmente ao condicionado, como parece pretender o compromisso firmado pelo ato investigativo. Isto será feito ao longo do desenvolvimento desta argumentação. Mas por ora vamos aceitar os elementos que estruturam a formulação da nossa hipótese não sejam realmente problemáticos.

Nestes termos, pode-se dizer inicialmente que dar conta de uma tarefa investigativa assim não é nada fácil. Basta ver que se, por exemplo, o nosso interesse recaísse sobre a forma narrativa do texto de Wittgenstein em geral não recolheríamos, em absoluto, nenhuma resposta transparente. A sua produção escrita tomou caminhos verdadeiramente labirínticos e cresceu como uma árvore gigante de galhos retorcidos ao longo de 27 anos de trabalho, somente interrompidos por um lapso de 11 anos em que o autor desistiu de fazer filosofia e se dedicou exclusivamente às atividades de jardinagem, ensino primário e arquitetura. Enquanto se manteve na atividade literária, ${ }^{1}$ seu processo de trabalho cotidiano consistiu em anotações manuscritas, correções destas anotações, datilografias provenientes destes resultados corrigidos, recortes destes datiloscritos e colagens em novos rearranjos, novas correções manuscritas sobre os datiloscritos já rearranjados, que se tornaram então novos datiloscritos, formando-se finalmente um emaranhado verdadeiramente bisonho. Não menos surpreendente é constatar que o desenlace final de todo este processo obsessivo de composição foi a publicação, em 1921, de apenas um único livro: o "Tractatus Logico-Philosophicus". Obteve-se, no entanto, um saldo restante de mais de 20.000 páginas de manuscritos e datiloscritos inéditos que foram confiados em testamento a três dos seus antigos alunos (Anscombe, Rhees e von Wright) para que os publicassem postumamente da maneira que melhor lhes parecesse. ${ }^{2}$

Nessa massa textual embaralhada há formas narrativas bem diferentes umas das outras. Presume-se que sejam mais ou menos correspondentes às modificações da sua perspectiva filosófica no decurso dos anos e às várias tentativas de publicar um novo livro que depusesse a respeito destas modificações. ${ }^{3}$ Acalento a hipótese de que todas estas formas narrativas provocam profundas surpresas na expectativa do leitor, caso ele as crie. Este é um fator narratológico que a partir de agora chamarei de imprevisibilidade e que, por conseguinte, concorre para provocar efeitos colaterais terapêuticos no leitor produzidos por obra do encontro fortuito em que se conforma a conexão entre escritor, texto e leitor. Veremos mais adiante que esta conexão pode ser compreendida como composta por três momentos distintos: (a) a pré-configuração do texto no campo da ação de que participa o autor, (b) a sua configuração posterior como representação desta ação, também ela uma ação, na forma da elaboração do texto, e (c) a reconfiguração final no horizonte de experiência daquele que empreende a leitura em outro contexto e munido de expectativas próprias.

\footnotetext{
${ }^{1}$ Como veremos abaixo, há sobejas evidências de que Wittgenstein pretendia escrever literariamente.

$2 \mathrm{Na}$ introdução à minha tradução das "Investigações Filosóficas" (texto ainda não publicado) encontra-se mais detalhadamente a história da composição do Nachlass (o legado literário de Wittgenstein). Disponível em: $<$ http://www.psicanaliseefilosofia.com.br/textos/InvestigacoesFilosoficas-Original.pdf> . Acesso em: 17jun. 2020.

$3 \mathrm{O}$ acesso à maior parte do Nachlass pode ser feito pelos Arquivos Wittgenstein da Universidade de Bergen: http://www.wittgensteinsource.com. Ali não encontramos, porém, as correspondências e as transcrições das aulas, materiais igualmente relevantes do seu legado publicados por outras editoras (cf. as referências bibliográficas ao final do capítulo).
} 
Os eventos que provêm da própria práxis são, até onde alcanço compreender, contingentes, já que poderiam ter se conformado de outra maneira. Aqui estamos no reino do puro "acontecimento", onde tudo é incerto e imprevisível. Podemos narrar um acontecimento, certamente, estabelecendo novamente um tipo de conexão entre préconfiguração, configuração e reconfiguração, mas outra narrativa dele é perfeitamente cabível. Por este mesmo motivo, toda a minha investigação poderia estar baseada sobre a célebre passagem a respeito do jogo de linguagem como parte de uma atividade ou de uma forma de vida (IF \$23), ${ }^{4}$ em que "inventar uma história e ler" se conta como um destes exemplos. Este ponto também será retomado neste texto, mas quero deixar a substância da discussão em particular para outro momento em outra possível publicação. Aqui pretendo ajustar o foco exclusivamente sobre o Anexo III da Parte I das "Observações Sobre os Fundamentos da Matemática", uma das suas narrativas que especificamente coloca em questão por via indireta o teorema (ou teoremas) da incompletude da aritmética de Gödel. Vou tentar demonstrar pelo menos estas três características narratológicas deste texto: (1) imprevisibilidade, (2) opacidade, e, (3) efeito terapêutico. Se elas estiverem corretas, poderemos, assim espero, sustentar o argumento da natureza conversiva do texto de Wittgenstein.

\section{Imprevisibilidade}

Quando nos deparamos com o AIII como um bloco textual autônomo não é muito difícil compreender estes três níveis formais de apresentação do material literário: (1) as suas subdivisões; (2) os seus movimentos narrativos internos; e, (3) as suas inter-relações com a Parte I da RFM e os seus outros dois anexos.

(1) Quanto às subdivisões de AIII, percebemos imediatamente que o bloco está subdivido em 20 seções. Elas foram numeradas por Anscombe, Rhees e von Wright, os herdeiros do espólio literário de Wittgenstein, por ocasião da publicação da $3^{a}$ edição revisada das RFM em 1978. Originalmente, AIII era um datiloscrito de apenas 10 páginas (TS 223), ${ }^{5}$ separado por Wittgenstein em 1938 de outro datiloscrito maior, este codificado como TS 221 e que hoje corresponde à Parte I das RFM. ${ }^{6}$ No TS 223, nos damos conta das seções não pela numeração, que originalmente está ausente do datiloscrito, mas pelo espaçamento regular de duas linhas entre os blocos de parágrafos que o autor costuma usar nos seus textos e que podemos compreender como indicativo de uma "seção" ou "observação". A A bem da verdade deve-se dizer que o TS 223 tem, de fato, apenas 19

\footnotetext{
${ }^{4}$ Utilizo um certo número de abreviaturas para os textos de Wittgenstein e para o "Principia Mathematica", de Russell \& Whitehead: AI, AII, AIII - Anexos I, II, e III da Parte I das "Observações Sobre os Fundamentos da Matemática”; IF "Investigações Filosóficas"; MS - Manuscrito do Nachlass; PM - Principia Mathematica; RFM - "Observações Sobre os Fundamentos da Matemática"; TLP _ "Tractatus Logico-Philosophicus”; TS - "Datiloscrito do Nachlass".

5 A codificação dos manuscritos, datiloscritos e ditados de Wittgenstein foi realizada por von Wright (1993).

${ }^{6}$ O TS 221 estava originalmente vinculado ao TS 220 e ambos formavam o que hoje se reconhece como a versão inicial das Investigações Filosóficas, um texto finalizado em 1938 e composto por versões originais das atuais seções $\$ \int \$ 1-189$ das IF e pelas seções $\iint$ 1-171 das atuais RFM junto com os seus três anexos.

7 Wittgenstein denomina estes blocos de reflexão como “observações” no primeiro parágrafo do prefácio das IF: “Redigi estes pensamentos todos como observações, parágrafos curtos. Às vezes em cadeias mais longas sobre o mesmo objeto, às vezes saltando, em mudança repentina, de um domínio para o outro”. As observações, palavra que o autor destaca em itálico no excerto, são unidades independentes com um ou mais parágrafos, separadas por espaço duplo das observações antecedente e subsequente quando é o caso, e que pode ter ou não com estas alguma continuidade temática. Um tema pode também reaparecer abordado sob ponto de vista diferente em lugares aleatórios do texto, formando assim na
} 
seções. A atual vigésima seção provém de outra fonte, o MS 159, pp. 24r-24v, redigido no mesmo ano da separação entre o TS 223 e o TS 221, mas só posteriormente acrescentado ao material datilografado pelos seus três alunos-editores. O TS 223 , por sua vez, provém do MS 118, pp. 105v-116v, escrito no outono de 1937 na isolada cabana construída pelo autor na região de Skjolden, a $300 \mathrm{~km}$ a noroeste de Bergen, no sudoeste da Noruega, onde começou a compor tanto o TLP, em 1913, como a primeira versão manuscrita das IF, o MS 142, em 1936.

(2) Deve-se dizer também que, numa segunda observação mais detida, percebe-se claramente as modulações internas do texto. De fato, há quatro movimentos dentro da peça narrativa como um todo, cada um deles subdividido em partes. O primeiro movimento compreende as seções $\iiint_{1-4}$ que começa pela consideração de jogos de linguagem imaginários em que ordens e perguntas são expressas como afirmações, sem que, por causa disto, suas sentenças logrem ser verdadeiras ou falsas; depois, na seção $₫ 2$, considera-se que a maioria das sentenças que proferimos, que são, de fato, afirmações, não necessariamente contêm funções de verdade embutidas, e que estas, por outro lado, são apenas um dos jogos que pode ser jogado com elas; um jogo de linguagem da ordem ou do comando, isto já é entretido na seção $\ 3$, poderia até ser jogado com funções de verdade; o que nos leva a admitir, na seção $\int 4$, que não se pode dizer que a prática da aritmética é necessariamente realizada com o intuito de proferir "proposições" no mesmo sentido usual de sentenças empiricamente verificáveis como verdadeiras ou falsas.

No segundo movimento, que vai das seções $\iint 5-7$, a narrativa conduz então o leitor a considerar os PM como um jogo de linguagem em que a proposição está vinculada a funções de verdade, isto é, se uma proposição é demonstrada no sistema de Russell, a demonstração é assumida naturalmente como prova da sua verdade. ${ }^{8} \mathrm{Na}$ seção $\mathbb{S}$, a pergunta é como, de fato, se aplica naquele jogo de linguagem a asserção de uma proposição, e a resposta é "ao final de uma das suas provas" ou como Pp (o símbolo de teorema ou axioma nas $\mathrm{PM}$ ); mas na seção $\int 7$ retorna a pergunta sobre a possibilidade de haver proposições verdadeiras naquele simbolismo, porém indemonstráveis, e a conversa entre os personagens sem antroponímia segue um certo número de variantes em que se cogita se demonstrabilidade e verdade de uma proposição em um jogo se efetivam ou não em outro jogo.

Inicia-se o movimento central, e terceiro, com a seção $₫ 8$, e segue quase até o final do excerto, na seção $\ 19$, estendendo para a consideração do leitor algumas possibilidades hipotéticas em que uma proposição $\mathrm{P}$, do sistema de Russell, pudesse ser considerada como verdadeira e indemonstrável, ou então demonstradamente falsa, e como nenhuma destas cogitações extemporâneas ao jogo de linguagem das PM faz qualquer sentido dentro do sistema de Russell, nem sequer como uma eventual contradição que pudesse ser útil como uma admoestação de final de jogo?.

totalidade do escrito uma figura de uma série de esboços de paisagens mal desenhados e entrecruzados que se assemelha mais a um álbum do que a um livro sistematicamente ordenado. Estas características estão descritas no prefácio das IF. ${ }^{8}$ Nas “Wittgenstein's Whewell's Court Lectures" (WITTGENSTEIN, 2017, p. 50-57) o leitor encontra este mesmo argumento e ainda outros similares aos que aparecem em AIII a respeito dos teoremas da incompletude de Gödel.

9 Particularmente, Wittgenstein não toma a eventual descoberta de uma contradição dentro do sistema como uma ameaça à consistência da matemática tal como dramaticamente pressuposto pelo modelo do "problema da decisão" de Hilbert, que pretendia encontrar um procedimento mecânico (o que hoje chamaríamos de "algoritmo") que pudesse decidir em um número finito de passos se uma fórmula é demonstrável, e portanto verdadeira, a partir somente dos axiomas e das regras lógicas. Desde 1930 (cf. Wittgenstein, 1967, p. 119-122; e tb. MS 108, p. 24-26) nosso autor pensa que a questão 
Finalmente, o último e quarto movimento, constituído apenas pela seção $₫ 20$, que reconduz o leitor à noção de jogos de linguagem possíveis, com os quais o texto já se havia demorado no primeiro movimento, para demonstrar agora que proposições da lógica construídas como se fossem peças de informação, isto é, como conjunto de sentenças que assumem a mesma forma de proposições empiricamente verificáveis, não têm nenhuma aplicação na prática cotidiana do cálculo.

(3) Deve-se ainda dizer, num terceiro nível de apresentação formal do texto, que não é preciso grande esforço também para perceber que os três anexos da Parte I, todos eles separados por Wittgenstein do TS 221, lidam, cada um deles, com diferentes formas pelas quais se vê a matemática pelo mesmo modelo da ciência empírica, quando, na prática, ela não seria, na visão de Wittgenstein, mais do que uma ciência normativa. Assim, AI critica a interpretação da dupla negação como uma questão exclusiva de significado, e procura mostrar como esses teoremas estão ligados a vários tipos de prescrições, como também a sutilezas e ao caráter de alguns jogos de linguagem; AII procura mostrar que se não há descobertas na matemática, que se o matemático não é realmente um descobridor, como o cientista natural, mas um inventor, como o filósofo e o artista, então tampouco poderia haver na sua atividade qualquer coisa de surpreendente, espantoso ou misterioso, ao contrário do que predominantemente se faz entender; e AIII toma os PM como um jogo de linguagem próprio cujas proposições não poderiam ser demonstradas em outro jogo em que elas não fazem mais sentido - entretanto, haveria sentido em pensar os próprios PM como um "jogo de linguagem”, isto é, tomar proposições lógicas, tais como $\mathrm{P}$, pelo "mero soar das proposições", como se fossem parte de um conjunto de atividades interligadas com sentenças que têm alguma aplicação na vida real?

Pois bem, se não parece haver nada de absolutamente incomum nos níveis (1), (2) e (3) em que se pode observar o AIII, onde estaria então o fator inesperado que nos causaria surpresa e constituiria o que qualificamos de imprevisibilidade da narrativa? Quais seriam os elementos que apareceriam como inabituais ao leitor e que lhe exigiriam uma maior diligência para manter-se no acompanhamento do texto, seguindo seus rastros sem descaminhos a fim de conduzir a expectativa de leitura a um resultado que o autor pretende que seja frustrante para provocar, com isto, um efeito colateral terapêutico? Se "inventar uma história e ler" é um jogo de linguagem (IF \23), como assinalamos, como é que na forma narrativa de AIII se incita o leitor a jogar um jogo a fim de conduzi-lo a um certo tipo de resultado propositadamente arquitetado pelo autor: a revelação do impulso que

\footnotetext{
de Hilbert está "mal colocada" porque não concebe a matemática como um jogo próprio, um sistema de proposições em que se uma contradição eventualmente aparece no interior de um cálculo, simplesmente se reformulam as regras naquele ponto e se continua com o jogo. Em vez disso, Hilbert propõe-se a criar uma nova prova metamatemática, uma demonstração de consistência em um outro jogo ou em um outro cálculo voltado para o cálculo, para garantir que a linguagem-objeto, o cálculo matemático em si, esteja livre de contradições, isto é, de que não se dê o caso de que " $\alpha$ e $\sim \alpha$ " possam ser demonstrados no interior do sistema. Nas palavras de Wittgenstein, Hilbert age como se agora nós já pudéssemos provar "que um cálculo é um cálculo" (WITTGENSTEIN, 1967, p. 175; cf. particularmente as seções \$S 11-14 do AIII onde Wittgenstein reflete a respeito de sentenças autorreferenciais, paradoxos e provas de impossibilidade). No mesmo sentido em que Wittgenstein compreende a proposta de Hilbert como um mal-entendido a respeito da prática do cálculo na matemática, também lhe parece, a meu ver, que os teoremas da incompletude estão malconduzidos em relação ao que realmente ocorre nos PM. Em ambos os casos trata-se a matemática como se ela fosse uma disciplina que produz conhecimento sobre "alguma coisa", e não como se o seu fim se consumisse em si mesma como atividade prática.
} 
orienta nossas perguntas pela falência do próprio projeto de respondê-las adequadamente ${ }^{10}$

Não é preciso exibir a totalidade do AIII para detectarmos detalhes de seu ineditismo e singularidade, fatores nítidos de surpresa e imprevisibilidade. Vejamos apenas os pormenores da trama argumentativa das seções $\iint 8$-10, que subdivido entre texto, voz (personagens) e enredo, para nos darmos conta disto: ${ }^{11}$

Seção $\int 8$

Imagino alguém que me pede um conselho; ele diz: “Construí uma proposição (vou designá-la como "P”) com os símbolos de Russell, e mediante certas definições e transformações pode-se interpretá-la como dizendo: 'P não é demonstrável no sistema de Russell'. Não teria que dizer então desta proposição: por um lado ela é verdadeira, por outro lado ela é indemonstrável? Por conseguinte, se assumimos que ela é falsa, então é verdadeiro que ela é demonstrável! E é claro que isto não é possível. E se ela é demonstrável, então é demonstrável que ela é indemonstrável. Portanto, ela só pode ser verdadeira, mas indemonstrável."

Assim como perguntamos: “demonstrável' em que sistema?”, temos também que perguntar: “verdadeira' em que sistema?”. 'Verdadeira no sistema de Russell' significa, como dissemos: demonstrada no sistema de Russell; e 'falsa no sistema de Russell' significa: demonstrado o oposto no sistema de Russell. - O que significa então o seu: "se assumimos que ela é falsa"? No sentido de Russell isto significa: 'se assumimos o oposto do que está demonstrado no sistema de Russell'; se esta é a sua assunção, então você abandonaria agora a interpretação de que ela é indemonstrável. E com esta interpretação eu compreendo a tradução nesta proposição em português. - Se você assume que a proposição é demonstrável no sistema de Russell, então ela é, por conseguinte, verdadeira no sentido de Russell, e a interpretação "P não é demonstrável" tem que ser abandonada novamente. Se você assume que a proposição é verdadeira no sentido de Russell, então segue-se o mesmo. Além disso: se a proposição deve ser falsa em um sentido diferente do que o de Russell: então ela não o contradiz por ser demonstrada no sistema de Russell. (O que significa "perder" no xadrez pode constituir a vitória em outro jogo.)
$\mathrm{N}$

G P é uma proposição construída com os símbolos de Russell

$P$ não pode ser falsa

P só pode ser verdadeira e indemonstrável

$\mathrm{N}$

A verdade ou demonstrabilidade de P depende do sistema em que está inserida

$\mathrm{T}$ Se P está no sistema de Russell, a assunção corresponde à conclusão ou à demonstração

$\mathrm{N}$

Se P deve ser falsa em outro sentido, então não está no sistema de Russell

\footnotetext{
${ }^{10}$ Em 1931, no MS 112, p. 24r, Wittgenstein anota que "O trabalho em filosofia é - como muitas vezes o trabalho na arquitetura - realmente mais um trabalho sobre si mesmo. Sobre as próprias concepções. Sobre como se vê as coisas. (E o que delas se espera)".

11 Todas as traduções de textos de Wittgenstein e de outros autores aqui citados são minhas.
} 


\begin{abstract}
Seção $\int 9$
O que significa então: que "P” e "P é

indemonstrável” sejam a mesma proposição? Significa que estas duas proposições em português têm, em tal e tal notação, uma expressão.
\end{abstract}

$\mathrm{T}$

$\mathrm{N} \quad \mathrm{P} \& \sim \Pi \mathrm{P}$ só são uma expressão em outra notação

\section{Seção $\$ 10$}

"Mas P não pode ser demonstrável, pois se assumimos que tivesse sido demonstrada, então estaria demonstrada a proposição de que ela não é demonstrável." Mas se isto fosse demonstrado, ou se eu acreditasse - talvez erroneamente - que o tivesse feito, por que não deixaria a prova valer e dizer que eu teria que retirar novamente minha interpretação de “indemonstrável”?
G

$$
(\Pi \mathrm{P} \rightarrow \sim \Pi \mathrm{P}) \rightarrow \sim \Pi \mathrm{P}
$$

N

$$
\begin{aligned}
& \text { Mas se }((\Pi \mathrm{P} \rightarrow \sim \Pi \mathrm{P}) \rightarrow \sim \Pi \mathrm{P}), \\
& \text { então por que não } \\
& ((\Pi \mathrm{P} \rightarrow \sim \Pi \mathrm{P}) \rightarrow \sim \Pi \mathrm{P}) \rightarrow \Pi \mathrm{P} ?
\end{aligned}
$$

Comento cada uma das colunas. (1) Quanto à primeira coluna, o texto não segue qualquer parâmetro de estilo já conhecido de escrita filosófica, nem mesmo com relação a textos anteriores do próprio autor. Trata-se de um texto dialógico ${ }^{12}$ e nitidamente hermético. Não há nenhuma preparação para introduzir e ambientar o leitor a respeito dos assuntos debatidos no decorrer das seções do AIII. A forma do diálogo presente no texto é também completamente diferente da tradição dos textos dialógicos da filosofia (Platão, Galileu, Hume): os personagens aqui não têm antroponímico e a irrupção das diferentes vozes na narrativa é súbita e imprevisível. Por isto, a dificuldade de leitura aumenta, pois não se percebe imediatamente a presença do dialogismo no texto, assim como tampouco se consegue distinguir muito claramente quem exatamente está falando quando se identifica a existência de um diálogo. É certo que as vozes comparecem na narrativa como consciências independentes da voz do próprio narrador e em embate com ele. Elas não lhe dão a razão, não se impressionam com ele e nem lhe concedem a vitória, o que faz com que a decisão final a respeito do contraditório seja dada exclusivamente ao leitor. A diferença deste detalhe é ainda mais marcante com relação aos textos dialógicos tradicionais da filosofia, pois nestes a palavra final é sempre outorgada a apenas um dos personagens, que repetem todos o modelo de Sócrates, o vencedor do embate dialógico. $\mathrm{Na}$ forma dialógica do texto de Wittgenstein, ao contrário, não há imposição nem sugestão do pensamento do autor. O leitor é quem escolhe o caminho mais adequado a seguir diante do panorama que observa.

\footnotetext{
12 Pichler (2004) foi o primeiro estudo a indicar que a mudança de estilo na escrita de Wittgenstein, de uma narrativa "olímpica" para uma narrativa "dialógica", deu-se no outono de 1936, quando começou a redigir as IF. Assim como também ressaltou (p. 145ss.), junto com Stern (2006, p. 206), o caráter polifônico da espécie de dialogismo presente nas IF. Deve-se, contudo, sublinhar a diferença entre o dialogismo puro e simples e o que se quer dizer com o termo "diálogo polifônico" (cf. BAKHTIN, 1981, p. 1-37). Cavell, por exemplo, talvez tenha sido o primeiro comentador a sugerir que o estilo dialógico era importante para a interpretação do texto das IF, mas ele conseguia apenas distinguir duas vozes no texto: a vOz da "tentação" e a voz da "correção" (CAVELL, 1976, p. 71). Mas no diálogo polifônico não há, por definição, nem "correção" nem "tentação", pois isto sugeriria um pensamento monolítico, retratado no que se considera como vOZ da "correção". No diálogo polifônico, em vez de "certo" e "errado", cada voz do texto mantém sua própria autonomia diante das outras vozes. Autonomia diante da vontade do narrador e até mesmo diante da finalidade do autor ao escrever o texto. Por isto, as ideias presentes no texto pertencem realmente às diferentes vozes, e o diálogo neste caso apenas registra o embate entre elas. A narrativa, por sua vez, não leva a nenhuma conclusão, nem diz quem está certo ou quem está errado. Cabe ao leitor decidir o que pensar.
} 
(2) Na segunda coluna, consigo distinguir três vozes, que arbitrariamente batizei de $\mathrm{N}$ (voz do narrador), G (voz Gödeliana), e T (voz de um terceiro interlocutor), de acordo com o que me parece ser o interesse de cada uma. Porém, esta subdivisão em três vozes é também muito discutível. Dependendo da forma como se lê o texto, o que se pode chamar de operação de reconfiguração, como já explicarei abaixo, as vozes mudam de dono e de interesse. Particularmente problemático neste caso é a distinção da terceira voz $(T)$. Na seção $\int 8$, fiz a identificação pela introdução do travessão que indica uma modulação ou aprofundamento do pensamento anterior e uma nova pergunta dirigida à voz G; e, na seção $\ 9$, identifico T pelo surgimento de uma pergunta dirigida, desta vez, a N. Mas não diríamos que $T$ existiria a não ser que representasse nitidamente outra consciência, outro pensamento, e não uma simples modulação ou autopergunta que qualquer voz poderia fazer normalmente por si mesma. Apenas postulamos a voz $\mathrm{T}$ porque estamos no contexto de uma polifonia, em que mesmo uma leve mudança de faceta já nos leva a uma diferença de perspectiva e, portanto, a outra consciência possível. ${ }^{13}$

(3) $\mathrm{Na}$ terceira coluna, vemos que as tramas e urdiduras do enredo são muito mais complicadas ainda. O grau de certeza do leitor diminui drasticamente sob este aspecto. Sobre o que os personagens estão falando? De que maneira eles estão falando? De que ponto de vista? Apenas faço uma tentativa de decifração, perfeitamente contestável, usando os símbolos P (proposição Russelliana), П (demonstrado), \& (operador lógico de conjunção), (operador lógico de negação), e $\rightarrow$ (operador lógico de implicação).

Justifico a hipótese da imprevisibilidade narrativa em AIII, portanto, pelo tipo de dialogismo, pelo tipo de polifonia e pelo enredo extremamente complicado do conteúdo posto em pauta. Certamente contribui para a complexidade do enredo o fato de que o leitor não tem como acompanhar, exclusivamente pelo excerto, alguns conceitos centrais entretidos pelas vozes na narrativa, o que o torna hermético. O que se quer dizer exatamente com as noções de "jogos de linguagem" ou de "prova matemática" ali brandidos? Que diferença o autor estabelece entre "proposições empíricas" e "proposições da matemática"? O que tem a ver este tipo de discussões com o que o autor já havia comentado em outro lugar sobre a questão da decidibilidade na aritmética? Tudo isto só pode ser acessado pela familiaridade com o Nachlass, aquela massa labiríntica de textos inéditos do autor apenas parcialmente publicada pelos seus herdeiros literários de maneira completamente arbitrária, como se fossem livros já acabados, para que o leitor possa finalmente formar alguma conjectura sobre a espécie de discussão ali entretida pelas vozes. Incluindo-se certamente neste conjunto as várias correspondências que trocou com amigos e colegas e as anotações das aulas que ministrou em Cambridge. No entanto, as outras discussões presentes no "Nachlass", as várias centenas delas, também são, por seu turno, formas narrativas complexas de variados tipos, e os seus temas igualmente se disseminam e se entrecruzam aleatoriamente por todos os lugares. Não há praticamente nenhuma discussão filosófica de Wittgenstein localizável exclusivamente em um só ponto do legado

\footnotetext{
13 Uma pessoa poderia, por exemplo, pensar consigo mesma: - "Vou comprar um novo sofá"; e, em seguida, perguntarse: - “Mas para quê, se o que tenho ainda é novo?". Evidentemente não se trata de duas pessoas conversando. É a mesma pessoa que reflete sobre possíveis objeções ao seu propósito inicial e impulsivo. No entanto, se há outra pessoa neste contexto que costuma criticar o impulso consumista do primeiro, temos que considerar a sua auto-objeção como a voz do outro no seu pensamento, incorporada por hábito. Neste sentido, o contexto do diálogo polifônico já presume pensamentos distintos, ainda que sejam ligeiramente distintos, e nos fornece a justifica para assumir diferentes vozes introjetadas.
} 
literário. Há que se ter, para uma boa compreensão de qualquer um dos seus textos tomados isoladamente, uma ideia clara do desenvolvimento e da variedade em que os seus temas de discussão se desenrolam e se entretocam em uma grande quantidade de pontos ao longo de todo o "Nachlass". Parece-me, portanto, que a expectativa do leitor necessariamente se surpreende e se frustra diante da imprevisibilidade dos textos do autor, diante do fato de que as suas formas são idiossincráticas, diante do fato de que nenhum dos seus escritos se apresenta de maneira repetitiva e reconfortante, levando o leitor a uma atitude mais passiva, como seria recomendável para textos que se pretendem converter em best-sellers ou, pelo menos, para textos que pretendem ser mais facilmente compreensíveis. Muito longe de ser previsível e reconfortante, a escrita de Wittgenstein surpreende porque não encontra parâmetro de comparação, e por isto demanda sempre um esforço extraordinário. São textos que só se pode ler quando o leitor se mune de vontade férrea.

\section{Opacidade}

Para avançarmos na investigação, temos que separar agora o tema da imprevisibilidade de outro que também me parece muito importante: a opacidade narrativa. Suponho que este conceito deva servir igualmente para esclarecer por que tomo os textos de Wittgenstein como "narrativas".

O conceito de "narrativa" não comporta as mesmas propriedades que distingo no conceito de "imprevisibilidade". Nos traços de imprevisibilidade destaquei apenas aspectos formais e singulares do texto: dialogismo, personagens e enredo. Agora cuido somente da visão global do nosso objeto, mais do que do foco nas particularidades e minudências formais. A "narrativa" é tomada aqui como a invenção de um enredo mediante o qual se opera uma síntese entre objetivos, causas e acasos que se reúnem sob "[...] a unidade de uma ação temporal total e completa” (RICOEUR, 2019, p. 2). Assim, acontecimentos múltiplos e dispersos são integrados, pela ação de uma imaginação produtiva, numa história inteira e finita. Evidentemente a variedade das narrativas, que abrangem principalmente os campos da história e da ficção, corresponde à diversidade dos gêneros literários produzidos pela inventividade humana. Existe todo tipo de narrativa, a sua variedade é muito abrangente. Mas aqui quero destacar sobretudo que a invenção narrativa é parte do agir humano e das suas formas de vida, portanto, subsumível à ideia do jogo de linguagem de "[...] inventar uma história; e ler" (IF \23), como já destaquei. Deste modo, alio às características formais do texto de Wittgenstein também as propriedades narratológicas de qualquer síntese entre objetivos, causas e acasos que se pode encontrar num enredo. Voltaremos ao conceito de "narrativa" no próximo tópico. Por ora nos interessa destacar a "opacidade narrativa".

Quanto a esta, há um lado, sugerido numa das acepções da palavra "opacidade", que designa obscuridade ou confusão de um texto. Não é exatamente isto o que se ressalta aqui. Ao contrário, pretende-se justamente evidenciar que narrativas podem ser opacas ou transparentes, mais ou menos como filmes, esculturas, representações arquitetônicas ou pictóricas também podem sê-lo. Para que nos demos conta desta característica, basta que as contemplemos ao modo de uma apresentação panorâmica ou sinóptica de um objeto pronto a ser examinado e descrito, tal como nos recomenda a übersichtliche Darstellung nas 
IF \122. A proposta agora seria então abordar a narrativa como expressão de um ponto de vista, como a maneira pela qual se representa um pensamento como uma fisiognomia (cf. ALMEIDA, 2015).

Para justificar este tópico, retomo de um modo próprio o modelo teórico pelo qual Lamarque (2014) distingue a narrativa literária ou artística da ordinária ou não-artística. E por uma razão muito simples: parece ser a maneira menos complicada para explicar "[...] por que há tantos Wittgensteins" (BILETZKI, 2003; STERN, 2006) sem cair na confusão conceitual que os comentadores vêm produzindo ultimamente a respeito da questão do estilo (cf. KAHANE; KANTERIAN; KUUSELA, 2007; KANTERIAN, 2012). Não é o estilo, apenas um aspecto formal, a agir por conta própria, como se fosse uma pessoa, que torna opaca ou transparente uma narrativa, e, por conseguinte, gera multiplicidade de interpretações distintas, mas, antes, a capacidade que tem a narrativa literária de não ser substituível por paráfrases quando o interesse do leitor coincide com o do autor em jogar o jogo de linguagem da leitura literária.

Quando a narrativa se torna opaca por causa da coincidência de interesses não se produzem paráfrases do conteúdo. Este se torna então irrecobrável e aumentam assim as divergências de leitura. Quando a narrativa, ao contrário, é transparente, então a paráfrase, tem curso livre, e o conteúdo se preserva ao longo das substituições entre as diferentes narrativas fazendo com que a concordância entre as diferentes leituras aumente. Por isto, a falta de paráfrases do conteúdo denota a opacidade narrativa, quer dizer, a insubstitutibilidade do conteúdo ou da leitura, e, por conseguinte, a dificuldade de troca entre narrativas e, assim, o aumento de visões opostas e de polissemia.

Para exemplificar o ponto, podemos observar que há certos filósofos cujo estilo de escrita apresenta dificuldades quase intransponíveis de leitura, não obstante não há tanto desacordo a respeito do que pretendem dizer. A filosofia de Deleuze, por exemplo, pode ter no máximo duas interpretações discordantes: ou é uma ontologia da diferença, ou é um empirismo transcendental; sobre Derrida ou Heidegger, os intérpretes também estão mais ou menos de acordo a respeito do que cada um quer dizer: desconstrução ou dessubstancialização como forma de metafísica, segundo o caso; Hegel tem uma interpretação de direita e outra de esquerda, e já levamos quase duzentos anos com estas duas visões. Já o texto de Wittgenstein, que, à diferença de todos estes, apresenta uma linguagem perfeitamente coloquial, pode ter várias interpretações absolutamente disparatadas entre si. Seu texto quase que não gera paráfrases, aparentemente só gera interpretações divergentes. E muitas delas. No livro de Biletzki (2003), por exemplo, contam-se mais de vinte interpretações distintas subdividas em cinco blocos e meio de similaridades temáticas que a autora denomina como "estações". Parece, deste modo, mais ou menos óbvio que o ponto-chave para a multiplicação de interpretações divergentes dos mesmos textos não é propriamente o estilo, isto é, a conjunção de aspectos singulares puramente formais e característicos do texto, como observamos no tópico anterior, mas o conluio do interesse do leitor com aquilo que vê e demarca em sua leitura:

[...] a opacidade de uma narrativa aumenta na medida em que o conteúdo da narrativa é considerado - sob certos interesses e sem dúvida sob especificações cada vez mais refinadas - como dependente da maneira de sua apresentação. (LAMARQUE, 2014, p. 11). 
Sob que condições uma "narrativa A", por exemplo, pode ser substituída por outra "narrativa B" e o conteúdo permanecer preservado? Digamos que o conteúdo de um relato sobre as consequências da Guerra Civil Russa, a partir de 1923 - vamos assumir que seja a "narrativa A" -, só pode ser substituído por outro com a preservação dos significados que abriga se o interesse de todos os leitores for o mesmo ou então parecido. Se a narrativa da guerra fosse composta por um historiador stalinista, encontraria ampla aceitação em sua comunidade ideológica. Uma nova narrativa composta a respeito da "narrativa A" por outro historiador stalinista, como uma recensão ou comentário, concordaria globalmente com aquela e com qualquer outra produzida na comunidade ideológica, de tal modo que, do ponto de vista do conteúdo, as novas narrativas B, C, D etc. poderiam ser substituídas umas pelas outras sem muitas objeções quanto ao que dizem. Em todo o processo, o relato das consequências da Guerra Civil Russa a partir de 1923 descrito na "narrativa A" estaria suficientemente claro para todos. Diferenças de detalhe seriam consideradas irrelevantes ou corriqueiras. Teríamos, no fundo, uma profusão de paráfrases. Mas se os interesses forem distintos, como, por exemplo, na recepção de uma dessas narrativas numa comunidade de trotskistas, a pressão sobre os detalhes formais do conteúdo provavelmente se tornaria mais exigente, e se criaria uma disputa pela, assim chamada, "interpretação correta". Deste modo, como defende Lamarque, "[...] podemos ler (ou interpretar) uma narrativa de maneira transparente ou opaca relativamente ao interesse que temos nela e ao tipo de atenção que damos à sua forma linguística" (LAMARQUE, 2014, p. 12).

Não obstante, um relato da Guerra Civil Russa, seja ele opaco ou transparente, não é uma narrativa de ficção, por mais literária que tenha sido a sua escrita. Trata-se sempre do gênero reconhecido como "narrativa histórica", por causa dos propósitos e da função social estabelecidos numa cultura para categorizar este tipo de recensão. O que, então, transformaria uma narrativa qualquer em "literária"? Que fatores provocariam o leitor a não mais considerá-la simplesmente como histórica, informativa ou corriqueira? Para Lamarque, estes fatores estão na densidade e na fineza da escrita, que, potencializam, pelos aspectos formais, a absorção do interesse do leitor e aumentam o grau de inseparabilidade entre forma e conteúdo. Consecutivamente, quando o interesse pelos detalhes da apresentação aparece, o texto é levado a tornar-se cada vez mais, por assim dizer, “imparafraseável”, e, assim também, "literário".

Mas não houve aqui uma inversão do que justamente acabei de dizer? É o leitor que descobre que a narrativa é "imparafraseável" ou é ele que, ao contrário, a lê propositadamente assim? Afinal de contas, podemos admitir sem esforço que é perfeitamente possível reproduzir de forma correta num livro de teoria literária, numa aula de graduação, ou até mesmo numa revista de cultura, uma narrativa literária real como, digamos, "Grande Sertão: Veredas", de Guimarães Rosa, em todos os seus intrincados e primorosos detalhes formais, sem que houvesse percepção de grandes discordâncias entre essas várias narrativas ou paráfrases. Todavia, digamos novamente que, embora sob certos interesses qualquer conteúdo pode ser parafraseado de alguma forma, quanto mais atenção se der às sutilezas formais da expressão literária, menos parafraseável se torna o conteúdo. O caso especial da narrativa literária é que ela sustenta muito bem o interesse literário de leitura pretendido pelo autor e pelo leitor em conjunção. Ou seja, o autor prepara o seu texto com tais e tais características para encontrar precisamente o leitor que se interessará por 
elas. Pelo que se pode compreender que ler literatura como literatura é uma prática desenvolvida em relação com o estabelecimento de certos valores literários no interior de uma forma de vida, ou, em termos mais wittgensteinianos, pode-se compreender que se joga um jogo de linguagem específico que ocorre, entre nós, no encontro do interesse do leitor de literatura, que não é qualquer leitor, com o modo de apresentação específico de uma obra que não é qualquer obra. Ler livros de teoria literária, ou ler um artigo sobre uma obra literária numa revista de cultura, é parte de outros jogos como, por exemplo, "descrever um objeto", "informar um acontecimento", "fazer conjecturas" ou "propor uma hipótese e prová-la" (IF \23). O que pode acontecer até mesmo com relação ao romance capital de Guimarães Rosa, que, neste caso, não encontrará o leitor literário. E, por outro lado, pode-se disputar acerca de marcas de estilo em um texto filosófico qualquer sem que isto não o transforme necessariamente em literário. É preciso que autor e leitor encontrem o mesmo interesse e que as divergências acerca do conteúdo se multipliquem para que um texto se caracterize como literário neste jogo de linguagem específico. Portanto, o modo como uma obra literária é constituída não é um acaso fortuito, mas um fator essencial para o estabelecimento da sua identidade e do seu valor, numa forma de vida particular, dentro de um certo jogo de linguagem de leitura.

Lamarque pede, por isso, que olhemos para as "regras do jogo", em vez da forma ou do conteúdo, para distinguirmos na narrativa literária uma intenção ou propósito por parte tanto do leitor quanto do autor. Ou então, dando um pouco mais de precisão ao raciocínio, o que deveríamos reparar, neste caso, é o modo como o conteúdo é constituído mediante sua apresentação e pelo tipo de leitor que sua leitura é capaz de sustentar (cf. LAMARQUE, 2014,p. 71-72). Desta maneira, Lamarque acompanha, sem saber, o conselho oferecido por McGuinness quando notou que o TLP e as IF sempre acenam para alguma coisa diferente daquilo que dizem: “[...] é essencial entender, quando lemos Wittgenstein, [...] que o importante não são os fatos, mas a maneira como os fatos são vistos ou apresentados" (McGUINNESS, 2006, p. 367). O que ocorre com os textos de Wittgenstein, segundo esta perspectiva, é que há conjuminância de interesses entre leitores e autor no encontro do texto propositalmente configurado com uma pluralidade de marcas formais de estilo que podem ser vistos e demarcados com diferentes pesos para determinar um certo tipo de interpretação ou de leitura imparafraseável com relação a outra leitura que eventualmente vê e demarca traços relevantes de maneira divergente da primeira. Produz-se, por assim dizer, diferentes sotaques, ou diferentes visões de aspecto. Diferentes atos ou jogos de linguagem de leitura que dão conta do interesse do leitor com relação à obra. Uma obra, digamos mais uma vez, intencionalmente preparada para nada sugerir ao leitor senão revelar, mediante o próprio ato de leitura, o seu comprometimento com a interpretação que responde pelo que faz e que é eventualmente divergente de outra interpretação do mesmo texto.

\section{Efeito Terapêutico}

Passemos adiante. Se buscamos agora indícios de que Wittgenstein discorreu sobre o interesse do leitor e do autor em seu legado literário, podemos constatar que sim, este autor sempre quis escrever para um tipo especial de leitor, e nunca para todos. Na seção $\mathbb{S}$ 
6.54 do TLP, ele se refere muito explicitamente àquele que o compreende, e não ao que compreende o livro: "Minhas proposições elucidam desta maneira: quem me entende acaba por reconhecê-las como contrassensos [...]" (WIT'TGENSTEIN, 2001, p. 281). No MS 109, p. 206, num esboço de prefácio para o novo livro que já pretendia publicar em 1931, redige: "Este livro foi escrito para aqueles que têm franca simpatia pelo espírito com que foi escrito". E no MS 136, p. 81a, em outro esboço de prefácio para o novo livro que ainda em 1948 pretendia publicar, diz que prefere que o livro "seja em breve esquecido pelos jornalistas filosóficos e fique reservado para um tipo mais nobre $<<$ melhor $>>$ de leitor". É preciso notar que o leitor ideal destes três diferentes excertos de épocas bem distintas nunca é o fiel reprodutor do conteúdo.

Temos sobejas evidências, por outro lado, de que Wittgenstein pretendia escrever literariamente, não só filosófica ou tecnicamente. Numa carta escrita em 1919 ao editor Ludwig von Ficker, enquanto ainda tentava publicar o TLP, comentou o seguinte a respeito da obra: "O trabalho é estritamente filosófico e ao mesmo tempo literário, mas não há nele nada desmesurado", e, em relação a isso, ainda acrescenta: "ninguém vai ler, nem muito menos entender" (WITTGENSTEIN, 1969, p. 33). Em 1934, anota no MS 115, p. 30, e no MS 146, p. 50, que a filosofia "só pode ser poetizada" (gedicht werden) - aqui devemos notar que o uso do verbo dichten (poetizar) no excerto não aponta para o "lírico", mas para o "literário" (cf. JANIK, 2018, p. 144ss.). Quatro anos mais tarde, em 1938, ainda escreve:

Se não quero ensinar um pensamento mais correto, mas um novo movimento de pensamento, então a minha finalidade é uma "transvaloração de valores", e eu volto a Nietzsche bem como à minha visão de que o filósofo deve ser um poeta (Dichter). (MS, 120, p. 145r).

Recolhidos os devidos indícios documentais sobre leitor e autor dentro de uma perspectiva geral, retornemos agora para o nosso texto específico. Imaginemos que aqui está o mundo do acaso, onde tudo é possível, e perguntemo-nos: que tipo de ação ali se desenrola?

Para sabermos, devemos, em primeiro lugar, levar bem mais a sério o trecho em que o autor nos diz: "Minha tarefa não é falar sobre, por exemplo, a prova de Gödel; mas falar dela em linha cruzada" (RFM, VII $\left.\int 19\right) \cdot{ }^{14}$ Nesta frase tomamos conhecimento sobre que tipo de incumbência Wittgenstein assume, e com que tipo de estratégia para isto se apetrecha, no ato de colocar as mãos no seu objeto de trabalho. E, deste modo, podemos perfeitamente conjecturar que o conteúdo do AIII não foi enredado naquelas precisas tramas e urdiduras exatamente por acaso. No MS, 109, p. 208-209, Wittgenstein declara explicitamente que pretende escrever para não ser entendido por qualquer leitor:

\footnotetext{
14 Todas as traduções desse trecho que pude consultar seguem a versão que deu Anscombe para o verbo alemão vorbeireden: no inglês consignou-se by-pass (WITTGENSTEIN, 1978), no francês prevaleceu esquiver (WITTGENSTEIN, 1983), e no espanhol, evitar (WITTGENSTEIN, 2007). Essa acepção é possível, mas considerando que o autor não usou outros termos também apropriados para quem quer evitar falar diretamente sobre algo, como vermeiden (evitar ou esquivar-se) ou umgehen (dar a volta), temos que desconfiar, pelo menos, que uma boa maneira de descrever a sua "tarefa" talvez fosse escolher a acepção "falar sem se dirigir diretamente ao tema", ou "falar sem se fazer entender", ou então "falar em linha cruzada".
} 
[...] Pois se um livro está escrito somente para alguns poucos, isto ficará claro pelo fato de que poucos o entenderão. O livro tem que separar automaticamente aqueles que o entenderão e aqueles que não o entenderão. [...] A coisa decente a fazer é: colocar uma chave na porta que atraia somente aqueles que serão capazes de abri-la $\&$ não seja notada pelo resto.

Tem que estar presente uma estratégia literária para o leitor que lê literariamente o texto, e deve-se prever também um conteúdo imparafraseável, dando vazão a interpretações distintas que depõem acerca de diferentes atos de leitura.

Que o conteúdo se tornou "imparafraseável”, é fato facilmente constatável. Há pouco tempo Matthíasson (2013) elencou e comentou, com generosas exemplificações, todas as diferenças de interpretação do AIII que pôde arregimentar para o seu trabalho. Vistas como um conjunto de comentários sobre exatamente o mesmo texto, não temos como evitar o espanto. Porque todas as interpretações são desencontradas no seu sincero propósito de demonstrar por que exatamente a visão que Wittgenstein tem sobre os teoremas de Gödel merece ser lida com especial consideração, e quais são as características relevantes desse texto. Depois de comentar rapidamente uma avalanche de publicações iniciais extremamente depreciativas, ${ }^{15}$ ocorridas sobretudo na década de 1950, o trabalho compara entre si as perspectivas de Shanker (1988), Floyd (1996, 2000, 2001), Steiner (2001), Rodych (1999, 2002, 2003) e Berto (2009a, 2009b). Nós poderíamos ainda acrescentar outras duas interpretações que lhe escaparam por terem sido publicadas posteriormente: Priest (2004) e Kienzler \& Grève (2016). Cada uma delas sustenta uma visão diferente uma da outra.

Vamos admitir que a polissemia sobrevém ao modo de um efeito colateral do interesse do leitor. Um leitor interessado lê com cuidado, e o texto interessado é também cuidadosamente preparado. Teríamos, então, leituras diferentes. Savickey já apontou enfaticamente que o engajamento do interesse do leitor na filosofia de Wittgenstein é decorrente do aspecto estético do texto: “Aqueles que buscam justificações ou explicações vão achar que os textos de Wittgenstein são triviais ou enfadonhos" (SAVICKEY, 2017, p. 32). Day é também outro destes autores que enfatiza o papel da mostração e do estético nos textos tardios de Wittgenstein para o despertar do aspecto e a modificação da atitude do leitor (cf. DAY, 1999; DAY, 2017). Altieri, na mesma trilha do engajamento do interesse pelo papel da imaginação na leitura de textos literários, ressalta igualmente o uso da narrativa como meio de expressão. O leitor se prende talvez pelo desafio do que the parece enigmático ou desafiador. Um pouco pelo modo da "imaginação produtiva" de Kant, que, à diferença da "imaginação reprodutiva", perfaz a operação de síntese do heterogêneo ou do amorfo, recebido na intuição, bem por fora dos trilhos de qualquer modelo prévio de categorização, e atua, portanto, livremente, outorgando ao seu objeto regras próprias que lhe decifram o enigma que tem diante de si, ou então que levem o jogo do desafio ao seu termo final. Diz-nos Altieri que, por isto, "[...] o mostrar é o domínio mais claro em que a imaginação joga papéis significativos” (ALTIERI, 2015, p. 23).

\footnotetext{
15 Mathíasson enumera Kreisel (1958), Bernays (1959), Goodstein (1957) e Anderson (1958), mas eu ainda colocaria na conta dos "filósofos jornalistas" Dummett (1978), Bays (2004) e Lampert (2006). Essas narrativas são perfeitamente substituíveis entre si. Por elas nos inteiramos simplesmente de que ou Wittgenstein nunca leu Gödel, ou não compreendeu os teoremas da incompletude.
} 
Mas de todos esses filósofos talvez seja Ricoeur, que desconhecia amplamente o trabalho de Wittgenstein, aquele que melhor compreendeu a narrativa como operação intrinsecamente ligada à ação e à temporalidade humanas, e que pode, assim, nos dar as pistas mais promissoras para entender a espécie de ação presente no modo de Wittgenstein praticar filosofia mediante jogos de linguagem de leitura. Não somente isto, mas também que efeitos esta prática produz no leitor e como tudo isto tem a ver com o acaso terapêutico. Provavelmente assim, resgatamos um pouco o substantivo "narrativa" do terreno pantanoso dos clichês em que quase invariavelmente se usa hoje em dia esta palavra.

Ricoeur se propôs como tarefa "[...] reconstruir o conjunto das operações pelas quais uma obra se destaca do fundo opaco do viver, do agir e do sofrer, para ser dada por um autor a um leitor que a recebe e assim muda seu agir" (RICOEUR, 2019, p. 94-95). Como é que nesta perspectiva se justifica que um leitor modifique sua atitude pelo ato de ler uma narrativa? Justamente porque por ali se conta como relação ocorrida dentro da mesma e singular cadeia operativa os três atores que até aqui vínhamos tratando em partes separadas: autor, texto e leitor. O leitor é o operador por excelência que, no seu ato de ler, assume a unidade do percurso que vai desde a pré-configuraşão da narrativa, passa pela sua própria configuração, e desemboca na refiguração desse conteúdo na sua experiência temporal singular (cf. RICOEUR, 2019). Esta operação é tratada como um "círculo narrativo" em seu livro, uma visão tipicamente hermenêutica, mas podemos entendê-la perfeitamente como uma integração ou continuidade pragmática que se constitui pelo próprio ato de ler. Se tomamos a narrativa como uma "imitação" ou "representação" da ação, tal como faz Ricoeur, então nesta integração instituída pelo ato de ler incorpora-se: (1) a aptidão para identificar as mediações simbólicas utilizadas pela narrativa (signos, regras, normas), que fazem parte da pré-configuração do texto; (2) a tessitura dos acontecimentos pelos fios narrativos como ato configurante de objetos, eventos ou conceitos, como síntese do heterogêneo, na configuração da narrativa; e (3), uma visão de aspecto quando o leitor atualiza a obra no horizonte da sua existência como reconfiguração: “[...] a obra narrativa é um convite a ver nossa práxis como [...]" (RICOEUR, 2019, p. 141). Não é sequer necessário para esta reatualização da obra no horizonte de experiência do leitor que a narrativa seja um texto transparente:

[...] certas narrativas podem visar não a esclarecer, mas a obscurecer e dissimular. Este seria o caso, entre outros, das Parábolas de Jesus que, segundo a interpretação do evangelista São Marcos, são ditas para não serem compreendidas pelos "de fora" e que [...] expulsam de modo igualmente severo de sua posição privilegiada "os de dentro" (RICOEUR, 2019, p. 130).

O fato é que tais fragmentos narrativos, atualizados pelo leitor, têm potencial incoativo, podem seguir na direção de histórias efetivas que o sujeito assume para si, colocando-as em confronto com posições pessoais anteriores e com suas próprias responsabilidades.

Resgatemos, para arrematar nosso relato, a já mencionada übersichtliche Darstellung (IF \ 122) em conjunto com AIII. O conceito de "apresentação panorâmica" é uma forte evidência de que o autor apresenta as coisas "como as vê". Em relação aos teoremas de Gödel, Wittgenstein tratou de expor uma visão sinóptica do uso das suas palavras, para 
que se pudesse enxergar "conexões" para as quais não só "encontrou", mas também “inventou”, elos intermediários. Mas, se este é o modo de apresentação do autor, também o é, imediatamente, do leitor, na medida em que é este quem o atualiza em sua leitura. Digo que se o leitor junta as pontas e saliências do que vislumbra nas filigranas do quadro de Wittgenstein, e recupera para si tenuidades e sutilezas quase invisíveis, forma-se para ele uma figura, um rosto, a dar expressão ao que vê.

No entanto, IF \ 122 termina surpreendentemente com uma pergunta posta entre parênteses: "(Isto é uma visão de mundo?)". Obviamente, a questão funciona como alerta: por causa das minudências da tapeçaria que examina, o leitor pode também, se quiser, devotar o mesmo empenho para ver outra figura. E, neste jogo de visão e cegueira de aspectos, também no despertar de novos aspectos da figura expressiva, o leitor se daria conta de diferenças, e, por conseguinte, de si e do que pensa. Esta é a oportunidade da mudança de atitude: porque a pergunta final parece insistir pela responsabilidade acerca do que vemos.

Nosso ponto principal, entretanto, depois de todo este longo percurso, ainda está surpreendentemente sem explicação: como muda o leitor do texto de Wittgenstein e se alcança sua finalidade terapêutica? E também, como disto participa o acaso? Vamos então tentar fugir de meios sub-reptícios de obtenção de depoimentos a favor da nossa causa. Admitamos por um momento que um texto literário seja imparafraseável. Teríamos então visões opostas dele, mas não necessariamente profusão de visões opostas, como é o caso com os textos de Wittgenstein. Não obstante, esta era a nossa pergunta de fundo: qual é a explicação para tantos Wittgensteins tão discordantes entre si? Devo confessar agora que não tenho resposta para esta pergunta, e nem sequer para a linha de discussão que costura a publicação deste volume: o acaso terapêutico. Aqui já caminhamos plenamente no escuro e toda a linha argumentação que se desenrolou até agora se perde no próprio labirinto da sua linguagem. Pode-se apelar, é claro, para uma particularidade do texto de Wittgenstein. Aparentemente a solidariedade entre imprevisibilidade e opacidade é mais alta neste caso do que em outros na literatura, talvez porque a sua narrativa seja, além de literária, carregada com o propósito específico de mudar a atitude do leitor. Deste modo, a satisfação da expectativa de leitura seria frustrada pelo choque da revelação de que, entre tantas interpretações possíveis, um efeito de contentamento literário não seria mais do que uma visão de mundo. Mas não há evidências para corroborar esta suspeita. Carecemos de documentos comprobatórios de que Wittgenstein trabalhou deliberadamente para gerar mais polissemia do que o normal em suas composições. Assim, tenho que aceitar que a hipótese que tentei responder até aqui não passa de mera petição de princípio. Estamos rodando em volta do vazio.

Pelo que, ao chegar à conclusão, posso apenas apontar para um único culpado: a minha leitura. Em outras palavras, a minha atitude como leitor ou o que faço enquanto leio como leio. E o que faço é olhar para o texto como um detetive. Mas falta o crime, faltam as evidências anatômicas e os dados empíricos que funcionariam como eixo da investigação. Portanto, nesta investigação não há eixo, ela só gira em falso. Mas e se agora "[...] damos uma virada em toda a nossa consideração" (IF \ 108)? Então o que passaríamos a ver em AIII é uma prática de falar sobre Gödel de uma certa maneira. Por quê? Para quê? Qual seria a necessidade disto? Bem, talvez Wittgenstein presumisse que a pergunta inicial de Gödel estaria mal colocada, talvez nosso autor quisesse dizer que Gödel 
desconsiderava com a sua atitude a prática real da matemática, como ela surge e com que propósito, e a interpretasse exclusivamente de acordo com um certo preconceito filosófico descolado da vida concreta. Um preconceito tão cego que talvez nem valesse mais a pena falar diretamente com ele, mas só com algum leitor com capacidade suficiente para divisar o ponto cego e neutralizá-lo pelo reconhecimento. Um preconceito talvez muito semelhante àquele com que vinha lendo até agora o texto de AIII.

\section{Referências}

ALMEIDA, J. J. A Singularidade das Investigações Filosóficas de Wittgenstein: Fisiognomia do Texto. Campinas: Editora da Unicamp, 2015.

ALTIERI, C. Reckoning with the Imagination. Wittgenstein and the Aesthetics of Literary Experience. Ithaca: Cornell University Press, 2015.

ANDERSON, A. Mathematics and the 'Language Game'. London, The Review of Metaphysics, v. 11, n. 3, p. 446-458, March, 1958.

BAKHTIN, M. Problemas da Poética de Dostoiévski. Tradução de Paulo Bezerra. Rio de Janeiro: Forense Universitária, 1981.

BAYS, T. On Floyd and Putnam on Wittgenstein on Gödel. New York, The Journal of Philosophy, v. 101, n. 4, p. 197-210, April, 2004.

BERNAYS, P. Comments on Ludwig Wittgenstein's Remarks on the Foundations of Mathematics. Reading, Ratio, v. 2, n. 1, p. 1-22, December, 1959.

BERTO, F. The Gödel Paradox and Wittgenstein's Reasons. Oxford, Philosophia Mathematica, v. 17, n. 2, p. 189-207, June, 2009a.

There's Something About Gödel: The Complete Guide to The

Incompleteness Theorem. London: Wiley-Blackwell, 2009b.

BILETZKI, A. (Over)Interpreting Wittgenstein. Dordrecht: Kluwer Academic Publishers, 2003.

CAVELL, S. The Availability of Wittgenstein's Later Philosophy. In: . Must We

Mean What We Say? A Book of Essays. Cambridge: Cambridge University Press, 1976. p. 44-72.

DAY, W. Philosophy and 'The Literary Question': Wittgenstein, Emerson, and Strauss on the Community of Knowing. 1999. Tese (Doutorado em Filosofia) Graduate School of Arts and Sciences, Columbia University, New York, 1999. 
The Aesthetic Dimension of Wittgenstein's Later Writings. In: HAGBERG, G.

(ed.). Wittgenstein on Aesthetic Understanding. London: Palgrave Macmillan, 2017. p. 3-29.

DUMMETT, M. Wittgenstein's Philosophy of Mathematics”. In: DUMMETT, M.

Truth and Other Enigmas. Cambridge: Harvard University Press, 1978. p. 166-185.

FLOYD, J. On Saying What You Really Want to Say: Wittgenstein, Gödel and the Trisection of the Angle. In: HINTIKKA, J. (ed.). From Dedekind to Gödel.

Dordrecht: Kluwer Academic Press, 1996. p. 373-425.

Prose versus Proof: Wittgenstein on Gödel, Tarski and Truth. Oxford,

Philosophia Mathematica, v. 9, n. 3, p. 280-307, October, 2001.

GOODSTEIN, R. Critical Notice of Remarks on the Foundations of Mathematics.

Oxford, Mind, v. 66, n. 264, p. 549-553, October, 1957.

JANIK, A. The Dichtung of Analyic Philosophy: Wittgenstein's Legacy from Frege and its Consequences. In: BENGTSSON, G. et alii (ed.). New Essays on Frege. Between Science and Literature. Cham: Springer International Publishing, 2018. p. 143-157.

KAHANE, G.; KANTERIAN, E.; KUUSELA, O. Wittgenstein and His

Interpreters. Essays in Memory of Gordon Baker. London: Blackwell Publishing, 2007.

KANTERIAN, E. Philosophy as Poetry? Reflections on Wittgenstein's Style. Kassel, Wittgenstein-Studien, v. 3, n. 1, p. 95-132, March, 2012.

KIENZLER, W.; GRÈVE, S. Wittgenstein on Gödelian 'Incompleteness', Proofs and Mathematical Practice: Reading Remarks on the Foundations of Mathematics, Part I, Appendix III, Carefully". In: GRÈVE, S.; MÁCHA, J. (ed.). Wittgenstein and the

Creativity of Language. London: Palgrave Macmillan, 2016. p. 76-116.

KREISEL, G. Wittgenstein's Remarks on the Foundations of Mathematics. Oxford, British Journal for the Philosophy of Science, v. 9, n. 34, p. 135-157, August, 1958.

LAMARQUE, P. The Opacity of Narrative. London: Rowman \& Littlefield, 2014.

LAMPERT, T. Wittgenstein's 'Notorious Paragraph' about the Gödel Theorem. In: GASSER, G., et alii (eds.). Papers of the $\mathbf{2 9}^{\text {th }}$ IWS. Kirchberg am Wechsel: AWLS, 2006, p. 168-171.

MATTTHÍASSON, Á. A Chalet on Mount Everest: Interpretations of Wittgenstein's

Remarks on Gödel. Tese (Master of SciencesThesis - Institute for Logic, Language and Computation, Amsterdam, University of Amsterdam), 2013, original inédito. 
MCGUINNESS, B. Wittgenstein: Philosophy and Literature. In: PICHLER, A.; SÄÄTELÄ, S. (eds.) Wittgenstein: The Philosopher and his Works. Frankfurt: Ontos Verlag, 2006. p. 367-381.

PICHLER, A. Wittgensteins Philosophische Untersuchungen: Vom Buch Zum Album. Amsterdam: Rodopi, 2004.

PRIEST, G. Wittgenstein's Remarks on Gödel's Theorem”. In: KÖBEL, M.; WEISS, B. (eds.). Wittgenstein's Lasting Significance. London: Routledge, 2004. p. 207-227.

RICOEUR, P. Tempo e Narrativa. v 1: A Intriga e a Narrativa Histórica. Tradução de Claudia Berliner. São Paulo: Ed. Martins Fontes, 2019.

RODYCH, V. Wittgenstein's Inversion of Gödel's Theorem. München, Erkenntnis, v. 51, n. 2/3, p. 173-206, November, 1999.

. Wittgenstein on Gödel: The Newly Published Remarks. München, Erkenntnis, v. 56, n. 3, p. 379-397, June, 2002.

. Misunderstanding Gödel: New Arguments about Wittgenstein and New Remarks by Wittgenstein. Genève, Dialectica, v. 57, p. 279-313, December, 2003.

SAVICKEY, B. Improvisation and Imagination in Wittgenstein's Investigations. In: HAGBERG, G. (ed.). Wittgenstein on Aesthetic Understanding. London: Palgrave Macmillan, 2017. p. 31-60.

SHANKER, S. Wittgenstein and the Turning-Point in the Philosophy of Mathematics. New York: State University of New York Press, 1987. . Wittgenstein's Remarks on the Significance of Gödel's Theorem. In: SHANKER, S. (ed.). Gödel's Theorem in Focus. London: Routledge, 1988. p. 155256.

STEINER, M. Wittgenstein as His Own Worst Enemy: The Case of Gödel's Theorem. Oxford, Philosophia Mathematica, v. 9, n. 3, p. 257-279, October, 2001. Empirical Regularities in Wittgenstein's Philosophy of Mathematics. Oxford, Philosophia Mathematica, v. 17, n. 1, p. 1-34, February, 2009.

STERN, D. How Many Wittgensteins?. In: PICHLER, A.; SÄÄTELÄ, S. (eds.)

Wittgenstein: The Philosopher and his Works. Frankfurt: Ontos Verlag, 2006. p. 205229. 
VON WRIGHT, G. The Wittgenstein Papers. In: WITTGENSTEIN, L. Philosophical Occasions 1912-1951. Edited by James Klagge and Alfred Norman. Indianapolis: Hacket Publishing Company, 1993. p. 480-515.

WITTGENSTEIN, L. Wittgenstein und der Wiener Kreis. Herausgegeben von. B. McGuinness. Oxford: Basil Blackwell, 1967.

Remarks on the Foundations of Mathematics. 3. ed. Translated by G. E. M. Anscombe. Oxford: Basil Blackwell, 1978.

Remarques sur les Fondements des Mathématiques. Traduit de l'allemand par M.-A. Lescourret. Paris: Gallimard, 1983.

Bemerkungen über die Grundlagen der Mathematik. Ludwig Wittgenstein Werkausgabe Band 6. Berlin: Surhkamp, 1984.

. Tractatus Logico-Philosophicus (Logisch-Philosophische Abhandlung. 3. ed. Tradução de Luiz Henrique Lopes dos Santos. São Paulo: Edusp, 2001.

Observaciones sobre los Fundamentos de la Matemática. Traducción de I. Reguera. Madrid: Alianza Editorial, 2007.

Wittgenstein's Whewell's Court Lectures. Cambridge, 1938-1941. Edited by Volker Munz \& Bernhard Ritter from the notes by Yorick Smythies. London: Wiley Blackwell, 2017. 